\title{
Electrode Material of Carbon Nanotube/Polyaniline Carbon Paper Applied in Microbial Fuel Cells
}

\author{
Chin-Tsan Wang, Ruei-Yao Huang, Yao-Cheng Lee, and Chong-Da Zhang
}

\begin{abstract}
Microbial fuel cells (MFCs) are promising clean energy sources for simultaneous recycling of organic waste while harvesting electricity. As for the different effects of electrode materials on the power performance of MFCs, a new material of electrode, carbon nanotube/polyaniline carbon paper (CNT/PANI carbon paper) was utilized and compared with other traditional carbon paper/cloth in this study. Results show that a lower ohmic loss and a better power performance were executed by using CNT/PANI carbon paper. These findings further exhibit its feasibility to improvement of power performance in MFCs.
\end{abstract}

Index Terms-Electrode, microbial fuel cells, carbon nanotube / polyaniline carbon paper.

\section{INTRODUCTION}

The exhaustion of petroleum stores and the impending energy crisis will result in the future destruction of the environment. To help prevent this, seeking clean and renewable energy to replace traditional petrochemical energy has been continued. Here, the microbial fuel cells (MFCs) are one of green energy sources because MFCs uses microorganisms as a substrate and possesses active electrodes using the microorganism metabolism to produce electricity. The working principle of a microbial fuel cell is similar to that of a fuel cell. But, the main difference between them is the microorganisms' function in the microbial fuel cell to carry out the energy conversion [1].

The microbial fuel cell can be divided into direct microbial fuel cells and indirect ones [2]-[4]. A typical MFC consists of an anode chamber and a cathode chamber separated by a proton exchange membrane (PEM) whose available source is multiple [4]-[7]. As for the electrode materials, graphite particles, graphite felt, carbon paper, carbon cloth, reticulated vitreous carbon (RVC) and carbon brush were often used previously.

Concerning the feature of different electrode material resulting in different activation polarization losses [1], [2], $\mathrm{Pt}$ and Pt black electrodes are superior to graphite, graphite felt and carbon cloth electrodes for power performance, but their costs are much higher [8]. Schröder et al., [9] reported that using a platinumized carbon cloth electrode in E. coli MFC with a current density of $0.84 \mathrm{~mA} / \mathrm{cm}^{2}$ would be greater than

Manuscript received October 23, 2012; revised January 18, 2013. This work was supported by National Science Council of the Republic of China, Taiwan. (Contract No. NSC-101-2221-E-197-006 and NSC-101-2622-E-004-CC3). In addition, a part of financial assistance was supported by National I Lan University (Contract No. 101TGA-2B )

The authors are with Department of Mechanical and Electromechanical Engineering, National I-Lan University, I-Lan, 26047, Taiwan (e-mail: ctwang@niu.edu.tw). that of using standard carbon cloth electrode whose value is $0.02 \mathrm{~mA} / \mathrm{cm}^{2}$. In addition, a value of electricity generation with $1.45 \mathrm{~mA} / \mathrm{cm}^{2}$ was obtained by using a platinumized carbon cloth electrode with polyaniline. Generally, Pt has a higher catalytic activity with regard to oxygen than graphite materials [10]-[12].

Several research groups have looked into improving MFC performances [13] and have actively investigated electrode modification. Park et al., [14] reported that the performance of an E. coli MFC was $1.41 \mu \mathrm{A} / \mathrm{cm}^{2}$ and could achieve up to $3.1 \mu \mathrm{A} / \mathrm{cm}^{2}$ in current density output by using a modified graphite electrode with Neutral Red. Additionally, Park and Zeikus, [15], [16] designed both NR-woven graphite and Mn (IV) graphite electrodes that served as mediators in their MFC reactors. Doping ions such as Fe (III) and/or Mn (IV) in the cathode also catalyzed the cathode reactions resulting in improved generation of electricity. The electron driving force generated was coupled with the equivalent ion cycles on the cathode. The principle for their catalytic activity is the same as that of electron shuttles [16]. This resulted in a four-fold increase in current output by using a Mn (IV) graphite anode compared to the woven graphite electrode alone. Niessen $e t$ al., [17], [18] reported that using the modified electrode with fluorinated polyanilines poly (2-fluoroaniline) and poly (2, 3, 5, 6-tetrafluoroaniline) could improve the electricity of an MFC. Qiao et al., [19] reported that the use of carbon nanotubes (CNT), with the addition of polyaniline (PANI) as an anode electrode and placed on an E. coli microbial fuel cell, could produce a maximum power density of $42 \mathrm{~mW} / \mathrm{m}^{2}$. Zhao et al., [20], [21] used Iron (II) phthalocyanine (FePc) and cobalt tetramethoxyphenyl-porphyrin (CoTMPP) as a cathode electrode and discovered that it had the same performance as that of using platinum metal electrodes. In the electrode of the cathode reaction, the power density of the MFC was $379 \mathrm{~mW} / \mathrm{m}^{2}$ by adding a platinum cathode and $369 \mathrm{~mW} / \mathrm{m}^{2}$ by adding a CoTMPP cathode [22]. Lowy et al., [23] reported that the performance of a seafloor microbial fuel cell had a power density of $95 \mathrm{~mW} / \mathrm{m}^{2}$ when using an AQDS modified graphite electrode with coated manganese ions $\left(\mathrm{Mn}^{2+}\right)$ and nickel ions $\left(\mathrm{Ni}^{2+}\right)$. In addition to the electrode material modification, the contact area of the electrode also affected the performance of the MFC [24], [25]. Using carbon brush in an air-cathode MFC for a reaction volume of carbon brush of $9.6 \times 10^{3} \mathrm{~m}^{2} / \mathrm{m}^{3}$, producing a maximum power density of $2.4 \times 10^{3} \mathrm{~mW} / \mathrm{m}^{2}$ [24].

To sum up, features of electrode material will affect the polarization losses and power performance. In this study a new material, carbon nanotube/polyaniline carbon paper (CNT/PANI carbon paper), acting as an electrode in MFCs would be applied and compared with the carbon paper, 
carbon cloth, and NR-woven carbon paper for realizing its effect of power performance.

\section{MATERIALS AND MethoD}

\section{A. Bacterial Culture}

In this study, a kind of Escherichia coli based on the consideration of easy to obtain and culture was selected as a biocatalyst and analyzed for the solution in the microbial fuel cell in spite of its electrochemical inactivity. The sample of BCRC No. 51534 E. coli obtained from the Bioresource Collection and Research Center (BCRC) would be utilized because of being able to provide a better performance in a MFC [26].

The gene type of the BCRC No.51534 Escherichia coli was F- supE44 lacY1 ara-14 galK2 xyl-5 mtl-1 leuB6 $\triangle$ (mcrC-mrr) recA13 rpsL20 thi-1 $\triangle$ (gpt-proA) 62 hsdSB20 $\lambda$ - and the culture medium of the BCRC No.51534 E. coli was a LURIA-BERTANI (LB) medium. The culture medium included 5 grams of extracted yeast, 10 grams of the protein Tryptone, 10 grams of sodium chloride $(\mathrm{NaCl})$, and 1 liter of de-ionized water. The temperature of the Escherichia coli culture was maintained at $37^{\circ} \mathrm{C}$ like the rest, but the $\mathrm{pH}$ value of the culture was kept within a range of 7.0-7.5.

Both a plate and liquid culture medium had to be prepared first, before the E. coli could be cultured. The nutrient agar for the plate culture medium was composed of 0.75 grams of beef extract, 1.25 grams of Peptone, 250 milliliters of de-ionized water, and 12.5 grams of agar that had been slightly mixed. The medium was put into an autoclave for 15 minutes at $121{ }^{\circ} \mathrm{C}$, and then removed to cool at room temperature. It was then divided into $15 \mathrm{ml}$ solution culture dishes and left to coagulate. The nutrient broth for the liquid culture medium was made of a mixture of 3 grams of beef extract, 5 grams of peptone, and 1000 milliliters of distilled water. The medium was put in the autoclave at $121^{\circ} \mathrm{C}$ for 15 minutes, then removed to cool at room temperature and left to coagulate. The LURIA-BERTANI (LB) medium for the plate culture medium and liquid culture medium followed the same procedure as that of the nutrient agar and nutrient broth medium.

The culturing process for the E. coli is addressed as follows:

1) Stroke the bacteria: Take out the E. coli and medium dishes from the refrigerator, and then stroke the bacteria on the plate medium dishes three times at laminar flow. Then put into the incubator at $37^{\circ} \mathrm{C}$ and raise for 12 hours.

2) Select the bacteria: Select a suitable E. coli from the third plate medium dish and then put it into the liquid culture medium for mixing. Then put into an incubator at $37^{\circ} \mathrm{C}$ with a speed of $200 \mathrm{rpm}$ and raise for 12 hours.

3) Fix amount of liquid culture: Take $10 \mu \mathrm{L}$ of liquid culture medium of the Escherichia coli and put it into the $100 \mathrm{~mL}$ fresh liquid culture medium when an OD value of 1.2 for BCRC No. 51534 is achieved.

4) Amplification culture: Take the $100 \mathrm{~mL}$ Escherichia coli liquid medium fixed amount of liquid culture and put it into the incubator at $37^{\circ} \mathrm{C}$ with a speed of $200 \mathrm{rpm}$ and raises for 18 hours.

\section{B. Modified Electrode}

The carbon nanotube/polyaniline carbon paper (CNT/PANI carbon paper) electrodes obtained are based on the substrate material of the carbon paper by modifying the conductive polymer polyaniline (PANI). This contains the carbon nanotubes (CNT) to enhance the electron transfer ability [27], [28]. In this study, the CNT/PANI solutions were manufactured and the procedure for production of carbon nanotube/polyaniline carbon paper electrode would involve the following steps:

1) Cutting the carbon paper electrodes into appropriate sizes and placing them on the glass slides.

2) Dropping the CNT/PANI solutions into the carbon paper electrode until it is fully soaked. In addition, it is important to avoid the CNT/PANI solutions spilling outside the glass.

3) The carbon paper electrode with the glass is heated at $80^{\circ} \mathrm{C}$ for 8 to 12 hours until the electrode fully dries

Although neutral red (NR) is old aspect of MFC operation, it was also used as the electron mediator because the electrons in an indirect microbial fuel cell need an electron mediator by which to make the electron transfer [2]. Therefore, the neutral red would be immersed into the carbon paper electrode to manufacture it into an NR-woven carbon paper electrode. This was because it would possess an electronic transmission media and thus prove effective to the electrode in the MFC [15].

\section{Microbial Fuel Cell Design}

The prototype of a microbial fuel cell with dimensions of $10 \mathrm{~cm} \times 6.2 \mathrm{~cm} \times 5 \mathrm{~cm}$ shown in Fig. 1 was made of Polymethylmethacrylate (PMMA). The anode and cathode chambers whose volume is $100 \mathrm{~mL}$ per chamber were separated by a proton exchange membrane (PEM). A Nafion-117 membrane whose surface area is $9 \mathrm{~cm}^{2}$ selected was used as the material for PEM. Prior to study, the membrane would first be soaked in a $5 \%$ hydrogen peroxide solution with a heat level of between $70^{\circ} \mathrm{C}-80^{\circ} \mathrm{C}$ sustained for 1 hour. The membrane would then be put into the de-ionized water to eliminate the residue that results from the hydrogen peroxide solution. Afterwards, it would be soaked in $1 \mathrm{M}$ of sulfuric acid at $70^{\circ} \mathrm{C}-80^{\circ} \mathrm{C}$ allowing the sulfate ions to unify on the proton exchange membrane. It will allow the hydrogen ions to have easier access to form into a hydrogen- proton exchange membrane.

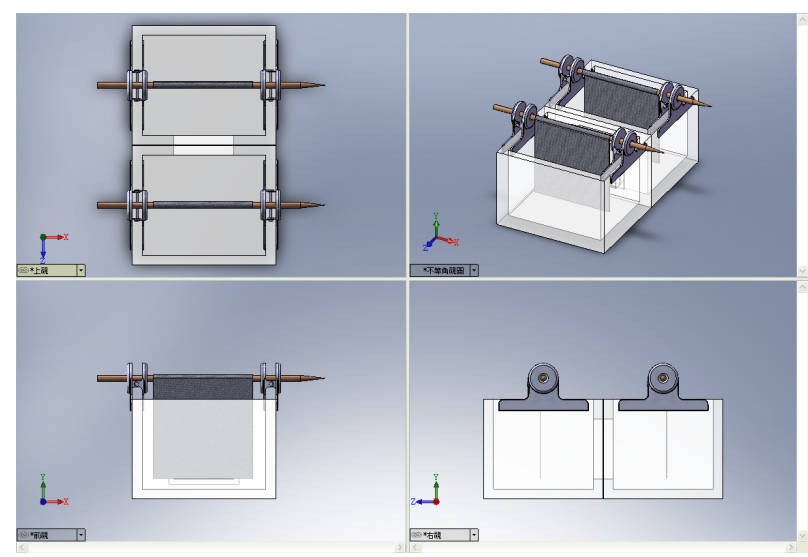

Fig. 1. The prototype of a microbial fuel cell. 
The total surface of anode compartment was filled with $100 \mathrm{~mL}$ of Escherichia coli solution and 0.37 grams of methylene blue. Conversely, an area of $80 \mathrm{~cm}^{2}$ is applied for each anode/cathode electrode. The methylene blue acted as the electron mediator was used in this study. An amount of $100 \mathrm{~mL}$ of $0.1 \mathrm{M}$ potassium ferricyanide was used for the cathode compartment. Finally, an operational temperature range of $23^{\circ} \mathrm{C}-25^{\circ} \mathrm{C}$ for the $\mathrm{MFC}$ and a value of $\mathrm{pH}=7.0$ for the $E$. coli culture was maintained.

\section{Measurement Analysis and Apparatus}

An electro-chemical workstation (Jiehan 5600, Taiwan) was applied to detect the I-V curve for exhibiting the performance of the MFCs. The power density, $\mathrm{P}_{\mathrm{An}}$, shown in equation (1) and calculated from the I-V curve and area of the anode, $\mathrm{A}_{\mathrm{An}}$, could further be changed into $\mathrm{P}_{\mathrm{w}}$ and is shown in equation (2). This was based on the consideration of the working voltage $\mathrm{V}$, area of anode $\mathrm{A}_{\mathrm{An}}$ and external resistance $\mathrm{R}_{\text {ext }}$. In addition, the working voltage $\mathrm{V}$ of the MFC was measured by the data acquisition system (Jiehan 5020, Taiwan) with the condition of the external resistance being $125 \Omega$. Total measuring time span was 72 hours. The electrochemical impedance spectroscopy (EIS) and impedance meter (HIOKI 3522-50, Japan) would be utilized for analyzing the performance of MFCs respectively.

$$
\begin{gathered}
P_{A n}=\frac{I V}{A_{A n}} \\
P_{w}=\frac{V^{2}}{A_{A n} R_{e x t}}
\end{gathered}
$$

\section{E. Morphology}

In this study investigating the relation between electrode morphology and the MFC is important and required because more information could be provided by electrode morphology to realize the physical mechanism of a MFC during the electrochemical process. Therefore, a scanning electron microscope, VEGA TS 5136MM, Tescan (Czech), would be utilized in this study.

\section{RESUltS AND DisCUSSIONS}

In this study, BCRC No.51534 E. coli cultured for 18 hours because of becoming the dominant species and being good for performance of MFCs [26] would be utilized at four kinds of electrodes for realizing the effect of MFC power performance, respectively. Result of Fig. 2 indicates that a larger power density with about $1574 \mathrm{~mW} / \mathrm{m}^{2}$ could be executed by the CNT/PANI and NR carbon paper electrode at the condition of voltage being $1.18 \mathrm{~V}$ and current as 12.8mA. As for the polarization curves of Fig. 2, the variation of current to voltage appearing in a linear form shows that the ohmic impedance resistance will be a significant factor in MFCs. The internal resistance [28], [29] resulted in ohmic losses in MFCs is $40.8 \Omega$ for a CNT/PANI carbon paper electrode. The internal resistance respected to a $\mathrm{CNT} / \mathrm{PANI}$ carbon paper electrode is lower than other studied cases and a better MFC performance would be expected. Concerning the working power density of the MFC respect to different electrode materials, results show that the CNT/ PANI carbon paper exhibits a better power performance $\left(1363 \mathrm{~mW} / \mathrm{m}^{2}\right)$ than the other studied cases of electrode material. Contrarily, the carbon cloth electrode shows a worse performance in comparison. These different performances of the MFC in the four kinds of electrodes could be realized from the images of micro-surface morphology by using SEM. Comparison of the power generation in this study with other research on the E. coli MFC with the same kinds of electrodes [15], [19]. The power density produced in the MFC system in this study is better than in other previous research. The E. coli MFC system designed in this study substantially improved electrical efficiency.

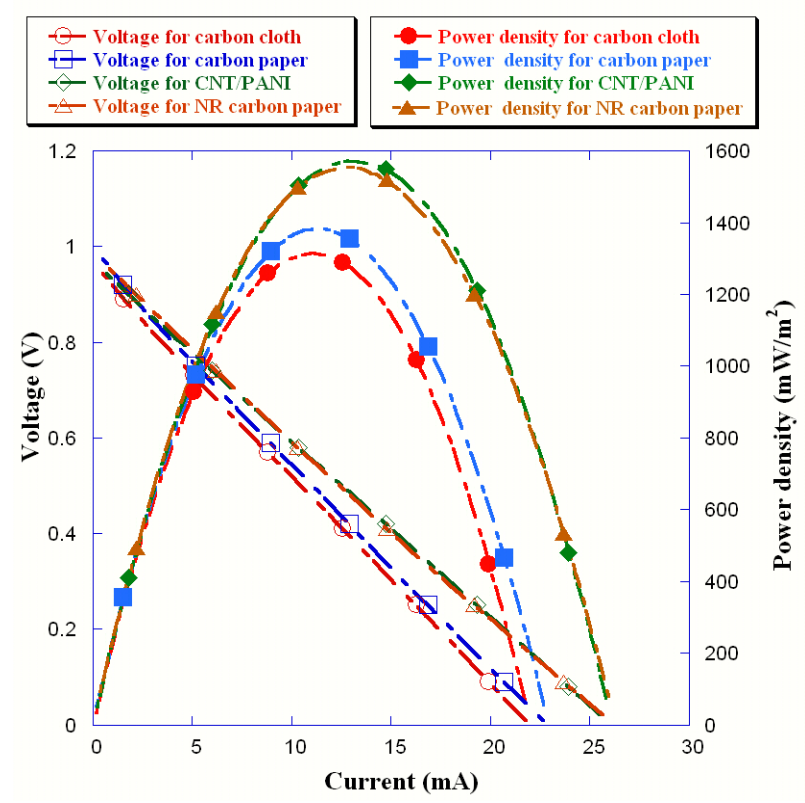

Fig. 2. Curves of V-I and curve of power density-I for four kinds of electrodes.

The comparison of surface morphology of a carbon cloth electrode is shown in Fig. 3A, with the image of a carbon paper electrode shown in Fig. 3B. Before conducting this study, we can see that the structure of carbon fibers for a carbon cloth electrode had a regular form. However, an irregular and dense one can be seen for the carbon fibers of a carbon paper electrode. Therefore, from the viewpoint of the micro morphology fiber, the surface area of the carbon paper electrode would be larger than in the case of the carbon cloth electrode. This could also prove a more efficient electricity creator than in the case of the carbon paper electrode. The different surface morphologies were captured and shown in Fig. 3A prior to the CNT/PANI carbon paper electrode experiment. In this case, a layer with carbon nanotubes / polyaniline polymer was placed on the electrodes. The carbon nanotubes / polyaniline polymer could improve the charge transfer effectiveness of the electrodes [19] because of its conductive polymer. Concerning the surface morphology of the NR-woven carbon paper electrode shown in Fig. 3D, a massive block-like shape was detected.

Observation on the experiments for the four types of electrodes is shown in Fig. 4. In the structure of those four types exists a large amount of particulate matter. This matter 
could possibly be attributed to the death of bacteria reunion material, substrate sediments or something unknown. Such matter could affect the performance of the MFC. Here, a modified electrode in CNT/PANI would be better for increasing MFC electricity generation. The equivalent circuit model of the MFC and Nyquist plot for the four kinds of electrode is made, and shown in Fig. 5. (A) and Fig. 5. (B), respectively. In the equivalent circuit model in Fig. 5. (A), the resistance $R_{s}$ means the internal resistance of the MFC. The elements include the electrode of the anode and cathode, proton exchange membrane and wire and electrolyte (bacteria solution). The ohmic loss originating from the internal resistance was the main factor affecting the performance of the MFC system because of the linear feature of its I-V curve. The capacitances $\mathrm{C}_{\mathrm{da}}$ and $\mathrm{C}_{\mathrm{ca}}$ are the electric double layer impedances between electrode and electrolyte related to anode and cathode. The capacitances would influence the charge transfer ability between the electrode and electrolyte related to anode and cathode, similar to activation loss. The capacitances $\mathrm{C}_{\mathrm{d} 1}$ and $\mathrm{C}_{\mathrm{d} 2}$ are the electric double layer impedances between electrode and stainless steel wire. These are related to the anode and cathode due to the design of the MFC system. From the results shown in Fig. 5. (B), a lower resistance $R_{s}$ was executed at an NR-woven carbon paper electrode, and the lower capacitances for $\mathrm{C}_{\mathrm{da}}$ and $\mathrm{C}_{\mathrm{ca}}$ were obtained for the CNT/ PANI carbon paper electrode. From the Nyquist plot, the MFC for the CNT/ PANI carbon paper electrode was found to have lower impedance than with other cases studied. To sum up, the MFC with a CNT/ PANI carbon paper electrode would provide the greatest electricity generation. These findings further exhibit its feasibility to improvement of power performance in MFCs [30].
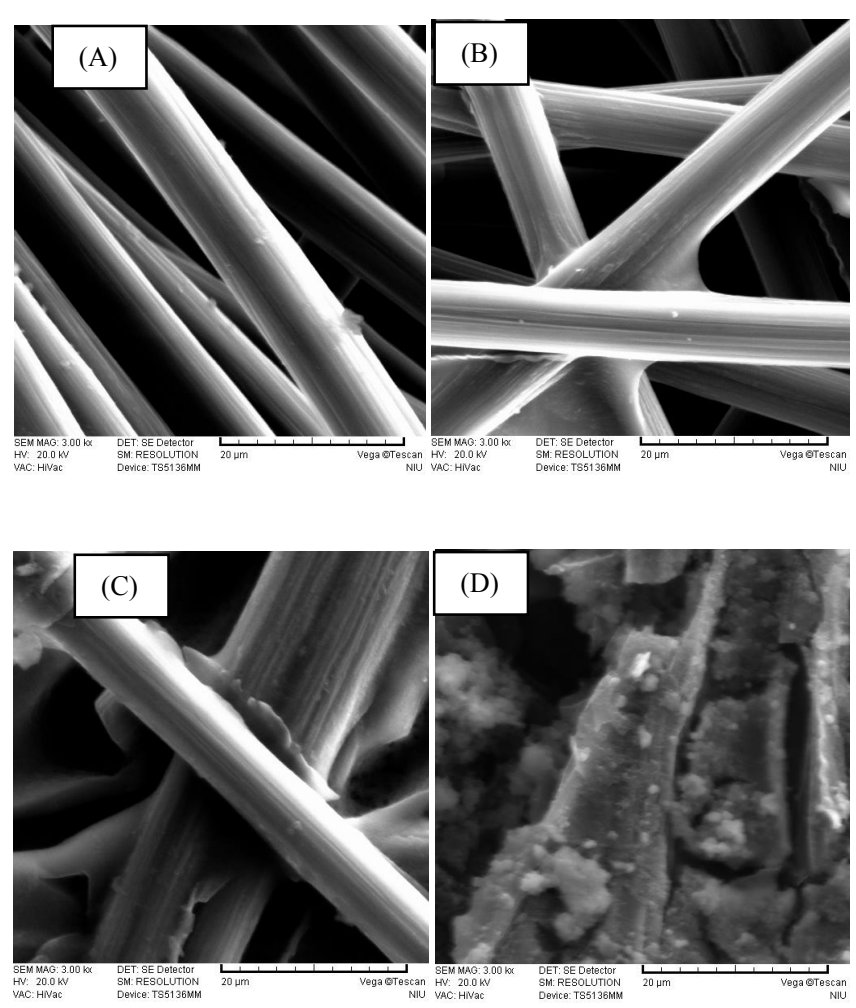

Fig. 3. SEM images shown before experiment for: carbon cloth electrode (A); carbon paper electrode (B); CNT/PANI carbon paper electrode (C); NR-woven carbon paper electrode (D). (magnification: 3000x)
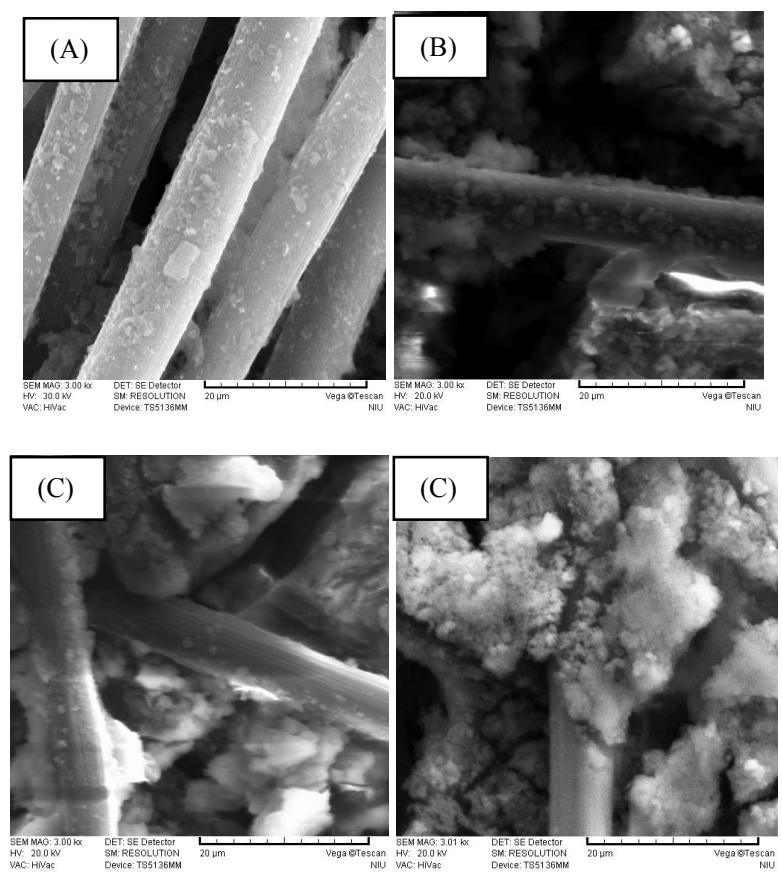

Fig. 4. SEM images shown after experiment for: carbon cloth electrode (A); carbon paper electrode (B); CNT/PANI carbon paper electrode (C);

NR-woven carbon paper electrode (D). (magnification: $3000 x$ )

(A)

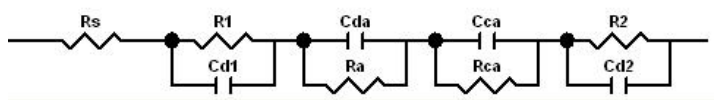

(B)

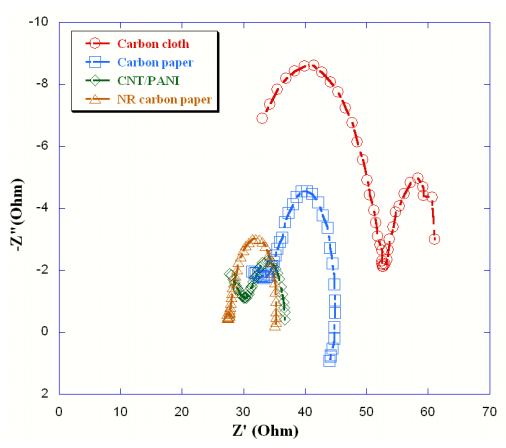

Fig. 5. (A) Equivalent circuit model of the MFC; (B) Nyquist plots showing for different kinds of electrodes. Impedance spectra recorded using a single sine wave modulation with $20 \mathrm{mV}$ amplitude.

\section{CONCLUSIONS}

In this study, four kinds of electrodes were applied to investigate the effect on the performance of a MFC in E. coli. Their materials were comprised of carbon paper, carbon cloth, carbon nanotube/polyaniline (CNT/PANI) and NR-woven carbon paper electrodes, respectively. Some results obtained are addressed as follows:

As for power performance of MFCs, a larger power density with about $1574 \mathrm{~mW} / \mathrm{m}^{2}$ was executed by using the $\mathrm{CNT} / \mathrm{PANI}$ electrode at the condition of voltage being $1.18 \mathrm{~V}$ and current as $12.8 \mathrm{~mA}$ because of a lower ohmic polarization losses and a larger contacting surface area of electrode. This shows that using the CNT/PANI as a modified electrode could give a positive effect on the power performance of 
MFCs. In addition, a linear feature of I-V curve was found to appear in MFC systems indicated an ohmic loss whose internal resistance was occupied, and proved to be the main factor influencing the power performance of a MFC. These observations are useful to improve the performance of $E$. coli MFCs.

\section{REFERENCES}

[1] F. Davis, and S. P. J. Higson, "Biofuel cells--Recent advances and applications," Biosens Bioelectron, vol. 22, pp. 1224-1235, 2007.

[2] B. E. Logan, and J. M. Regan, "Electricity-producing bacterial communities in microbial fuel cells," Trends in Microbiology, vol. 14, pp. 512-518, 2006

[3] K. Rabaey, and W. Verstraete, "Microbial fuel cells: novel biotechnology for energy generation," Trends Biotechnol, vol. 23, pp. 291-298, 2009.

[4] Z. Du, H. Li, and T. Gu, "A state of the art review on microbial fuel cells: A promising technology for wastewater treatment and bioenergy," Biotechnol Adv, vol. 25, pp. 464-482, 2007.

[5] N. Trinh, J. Park, and B. W. Kim, "Increased generation of electricity in a microbial fuel cell using Geobacter sulfurreducens," Korean J Chem Eng, vol. 26, pp. 748-753, 2009.

[6] K. Rabaey, N. Boon, S. D. Siciliano, M. Verhaege, and W. Verstraete, "Biofuel cells select for microbial consortia that self-mediate electron transfer," Appl Environ Microbiol, vol. 70, pp. 5373-5382, 2004.

[7] J. Y. Lee, N. T. Phung, I. S. Chang, B. H. Kim, and H. C. Sung, "Use of acetate for enrichment of electrochemically active microorganisms and their 16S rDNA analyses," FEMS Microbiol Lett, vol. 223, pp. 185-191, 2003.

[8] I. A. Ieropoulos, J. Greenman, C. Melhuish, and J. Hart, "Comparative study of three types of microbial fuel cell," Enzyme Microb Technol, vol. 37 , pp. 238-245, 2005

[9] U. Schröder, J. Nießen, and F. Scholz, "A generation of microbial fuel cells with current outputs boosted by more than one order of magnitude," Angew Chem Int Ed, vol. 42, pp. 2880-2883, 2003.

[10] H. Moon, I. S. Chang, and B. H. Kim, "Continuous electricity production from artificial wastewater using a mediator-less microbial fuel cell," Bioresour Technol, vol. 97, pp. 621-627, 2006.

[11] S. Oh, B. Min, and B. E. Logan, "Cathode performance as a factor in electricity generation in microbial fuel cells," Environ Sci Technol, vol. 38, pp. 4900-4904, 2004.

[12] J. K. Jang, T. H. Pham, I. S. Chang, K. H. Kang, H. Moon, K. S. Cho, and B. H. Kim, "Construction and operation of a novel mediator- and membrane-less microbial fuel cell," Process Biochem, vol. 39, pp. 1007-1012, 2004.

[13] E. Zhang, W. Xu, G. Diao, and C. Shuang, "Electricity generation from acetate and glucose by sedimentary bacterium attached to electrode in microbial-anode fuel cells," J Power Sources, vol. 161, pp. 820-825, 2006.

[14] D. H. Park, S. K. Kim, I. H. Shin, and Y. J. Jeong, "Electricity production in biofuel cell using modified graphite electrode with Neutral Red," Biotechnol Lett, vol. 22, pp. 1301-1304, 2000.

[15] D. H. Park, and J. G. Zeikus, "Improved fuel cell and electrode designs for producing electricity from microbial degradation," Biotechnol Bioeng, vol. 81, pp. 348-355, 2003.

[16] D. H. Park, and J. G. Zeikus, "Impact of electrode composition on electricity generation in a single-compartment fuel cell using Shewanella putrefaciens," Appl Microbiol Biotechnol, vol. 59, pp. $58-61,2002$.

[17] J. Niessen, U. Schröer, M. Rosenbaum, and F. Scholz, "Fluorinated polyanilines as superior materials for electrocatalytic anodes in bacterial fuel cells," Electrochem Commun, vol. 16, pp. 571-575, 2004.

[18] J. Niessen, F. Harnisch, M. Rosenbaum, U. Schröer, and F. Scholz, "Heat treated soil as convenient and versatile source of bacterial communities for microbial electricity generation," Electrochem Commun, vol. 8, pp. 869-873, 2006.

[19] Y. Qiao, C. M. Li, S. J. Bao, and Q. L. Bao, "Carbon nanotube/polyaniline composite as anode material for microbial fuel cells," J Power Sources, vol. 170, pp. 79-84, 2007.

[20] F. Zhao, F. Harnisch, U. Schröer, F. Scholz, P. Bogdanoff, and I. Herrmann, "Application of pyrolysed iron(II) phthalocyanine and CoTMPP based oxygen reduction catalysts as cathode materials in microbial fuel cells," Electrochem Commun, vol. 7, pp. 1405-1410, 2005.

[21] F. Zhao, F. Harnisch, U. Schröder, F. Scholz, P. Bogdanoff, and I. Herrmann, "Challenges and constraints of using oxygen cathodes in microbial fuel cells," Environ Sci Technol, vol. 40, pp. 5193-5199, 2006.

[22] S. Cheng, H. Liu, and B. E. Logan, "Power densities using different cathode catalysts (Pt and CoTMPP) and polymer binders (Nafion and PTFE) in single chamber microbial fuel cells," Environ Sci Technol, vol. 40, pp. 364-369, 2006.

[23] D. A. Lowy, L. M. Tender, J. G. Zeikus, D. H. Park, and D. R. Lovley, "Harvesting energy from the marine sediment-water interface II: Kinetic activity of anode materials," Biosens Bioelectron, vol. 21, pp. 2058-2063, 2006.

[24] B. E. Logan, S. Cheng, V. Watson, and G. Estadt, "Graphite fiber brush anodes for increased power production in air-cathode microbial fuel cells," Environ Sci Technol, vol. 41, pp. 3341-3346, 2007.

[25] S. E. Oh, and B. E. Logan, "Proton exchange membrane and electrode surface areas as factors that affect power generation in microbial fuel cells," Appl Microbiol Biotechnol, vol. 70, pp. 162-169, 2006.

[26] C. T. Wang, W. J. Chen, and R. Y. Huang, "Influence of growth curve phase on electricity performance of microbial fuel cell by Escherichia coli," Int J Hydrogen Energ, vol. 35, pp. 7217-7223, 2010.

[27] H. Liu, S. Cheng, and B. E. Logan, "Production of electricity from acetate or butyrate using a single-chamber microbial fuel cell," Environ Sci Technol, vol. 39, pp. 658-662, 2005.

[28] B.E. Logan, Microbial fuel cell, New Jersey: John Wiley \& Sons, 2008, pp. 62-76.

[29] B. E. Logan, B. Hamelers, R. Rozendal, U. Schröder, J. Keller, S. Freguia, P. Aelterman, W. Verstraete, and K. Rabaey, "Microbial fuel cells: methodology and technology," Environ Sci Technol, vol. 40, pp. 5181-5192, 2006.

[30] J. R. Rao, G. J. Richter, F. Von Sturm, and E. Weidlich, "The performance of glucose electrodes and the characteristics of different biofuel cell constructions," Bioelectroch Bioener, vol. 3, pp. 139-150, 1976.

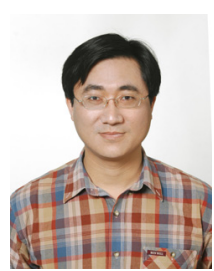

Chin-Tsan Wang was born in 1970 and graduated from National Cheng Kung University, Taiwan for his Bachelor, Master and $\mathrm{Ph}$.D degree during the period of 1992 to 2000. Now he works in National I Lan University, Taiwan. As for his present studying filed, Microbial fuel cell, Micro fluidic device and Flow slab of fuel cell are the major studying topics.

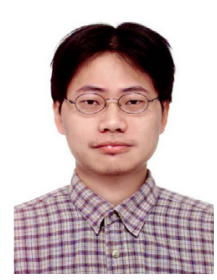

Ruei-Yao Huang was born in 1978 and graduated from Nation I Lian University, Taiwan for his master degree. His research is on power performance of microbial fuel cells in E-coli.

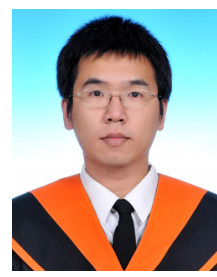

Yao-Cheng Lee was born in 1987 and a graduated student of National I Lan University now. His study is on design of rumen microbial fuel cells.

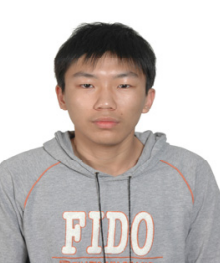

Chong-Da Zhang was born in 1989 and a graduated student of National I Lan University now. His research is about Investigation of sediment microbial fuel cells. 